\title{
Postvolcanic Aerosols: Measurements of Altitude and Particle Sizes with Twilight-Sky Polarimetry
}

\author{
O. S. Ugolnikov ${ }^{a, *}$ and I. A. Maslov ${ }^{a, * *}$ \\ ${ }^{a}$ Space Research Institute, Russian Academy of Sciences, Moscow, 117997 Russia \\ *e-mail: ougolnikov@gmail.com \\ **e-mail:imaslov@iki.rssi.ru \\ Received February 28, 2020; revised April 12, 2020; accepted May 29, 2020
}

\begin{abstract}
The intensity and polarization of the twilight-sky background were measured during the epoch of "purple lights" after the Raikoke volcanic eruption in the summer of 2019. The increase in brightness paired with the decrease in polarization was registered, and the changes were especially noticeable in the dusk segment. The altitude distribution of aerosol particles and their mean size were found with previously developed techniques. The median radius of the lognormal distribution $(0.11 \mu \mathrm{m})$ is typical of the background conditions or weak eruptions; however, the aerosols were mostly concentrated in the upper troposphere and near the tropopause rather than in the stratosphere. From comparison with satellite data obtained almost a decade ago after similar eruptions (like those of the Kasatochi volcano and others), it has been shown that the properties of their aerosols are similar, which confirms that the purple light phenomenon observed in 2019 was of volcanic origin.
\end{abstract}

DOI: $10.1134 / \mathrm{S} 0010952521020076$

\section{INTRODUCTION}

Stratospheric aerosol has been in the focus of experimental and theoretical studies since its discovery [1]. According to balloon measurements, the stratospheric aerosol differs from water in chemical composition; consequently, it appears at temperature and pressure values that do not allow water vapor to be crystallized [2]. Sulfate particles may be produced from $\mathrm{SO}_{2}$ of volcanic origin if the latter reaches the stratosphere (the chemical processes are described in paper [3]). This explains the enhancement in the concentration and the size of particles after strong eruptions, such as those of the El Chichón and Pinatubo volcanos in 1982 and 1991, respectively [4].

The scattering of solar light by aerosol particles induces optical phenomena that can be observed at twilight, when the stratosphere is still illuminated by the Sun, while the troposphere has been already covered by the Earth's shadow. The "purple light" effect was observed after the Krakatau volcanic eruption in 1883 [5], long before a direct discovery of aerosol particles in the stratosphere. The light scattering of particles is described by the Mie theory, and it exhibits no excess in the red spectral range if the particles are smaller than $0.3 \mu \mathrm{m}$ in size. The dusk becomes purple due to the absorption of solar radiation in the Chappuis ozone bands (in the yellow-green range) and the Rayleigh extinction (mainly in the violetblue range).
However, during volcanically quiescent epochs, the aerosol concentration does not completely vanish. Background aerosol particles have been directly analyzed in balloon experiments [6]. Their chemical composition is the same as that of postvolcanic aerosols, they appear at an altitude of approximately $20 \mathrm{~km}$, and their mean radius is about $0.1 \mu \mathrm{m}$. At the same time, the postvolcanic aerosol is observed slightly lower (except the cases of strong eruptions); and its particles are larger after strong eruptions [7]. The effect of purple lights was also observed during the volcanically quiescent periods [8].

Nonvolcanic sulfate aerosol particles may originate from carbonyl sulfide (OCS) [9]. Due to a higher threshold of dissociation and oxidation, OCS requires a larger solar radiation flux in the UV range to produce sulfate particles, which explains the altitude difference between the background and volcanic aerosols [10]. No noticeable trends in the background aerosol amount have been revealed from the balloon measurements performed for several decades [6]; however, its vertical optical thickness started to increase in the 2000s, after the eruption products of the Pinatubo volcano had been already removed from the stratosphere [11]. This phenomenon was considered to be possibly anthropogenic [12], since the OCS concentration in the atmosphere increased relative to that in the preindustrial epoch [13]. However, the growth of the aerosol amount could also be connected with the moderate volcano eruptions in the 2000s [14]. Volcano 
eruptions in the tropics (such as those of the Rabaul and Nabro volcanos in 2006 and 2011, respectively) may induce a global effect due to the Brewer-Dobson circulation. In the case of the Nabro volcano, the plume could reach the stratosphere due to the monsoon transport [15]. Volcano eruptions in the Northern Hemisphere (such as those of the Kasatochi, Sarychev Peak, and Eyjafjallajökull volcanos in 2008, 2009, and 2010, respectively) produce a noticeable effect at high northern latitudes. Since the tropopause is substantially lower there than in the tropics $(11-12 \mathrm{~km})$, a moderate eruption may introduce a substantial amount of sulfur dioxide into the stratosphere.

The issue of the causes of growth in the stratospheric aerosol level in the first decade of the 21st century was to be solved during the next decade, which turned out to be quieter as regards volcanic activity. Some decrease in the vertical optical thickness of the aerosol was observed even in the early 2010s [16, 17]. Polarization measurements of the twilight-sky background revealed the negative trend in the optical thickness lasting for 8 years, which actually confirmed the volcanic nature of the changes that occurred in the 2000s [18].

On June 21, 2019, the eruption of the Raikoke volcano $\left(48.3^{\circ} \mathrm{N}, 153.3^{\circ} \mathrm{E}\right)$ on the Kuril Islands (Russia) produced a stratospheric effect that was the strongest in the Northern Hemisphere after the Nabro eruption in 2011. According to the data of the Global Volcanism Program [19], the plume reached altitudes of about $13 \mathrm{~km}$. The tropopause altitude above the volcano amounted to $12 \mathrm{~km}$, as was estimated from the temperature data of the Microwave Limb Sounder (MLS) onboard the Earth Observing System (EOS) Aura satellite [20]. In the late summer and the fall of 2019, after the $\mathrm{SO}_{2}$ cloud had spread over the Northern Hemisphere, the effects of purple lights were observed. To confirm their volcanic origin, the altitudes and particle sizes of the aerosol should be measured and compared to the corresponding quantities in the epochs of similar eruptions of such volcanos as Kasatochi and Sarychev Peak. In this paper, we perform this comparison on the basis of the analysis of the sky background polarization and the technique developed for studying the stratospheric aerosol [18].

\section{OBSERVATIONS}

The intensity and polarization of the twilight-sky background were measured with a wide-angle polarization camera, which was placed in Moscow oblast $\left(55.2^{\circ} \mathrm{N}, 37.5^{\circ} \mathrm{E}\right)$. The camera was described in papers [21, 22]. The camera's field of view is $140^{\circ}$, and the observational conditions restrict the zenith angle of the considered points of the solar vertical circle $\zeta$ by a range of $\pm 50^{\circ}$. The observations are carried out in the spectral band with an effective wavelength of $540 \mathrm{~nm}$ and a full width at half maximum (FWHM) of $90 \mathrm{~nm}$. The camera is switched on before sunset, and it con- tinues working till morning. The exact position of the camera, the field curvature, and the atmosphere transparency are controlled by the positions of stars in the images of the night sky.

In the summer of 2019, the weather conditions were bad, which restricted the number of observations. This paper is based on the analysis of the moonless morning twilights observed on September 10 and 12, 2019 , and their comparison to the analogous morning data obtained in the fall of 2018.

Figure 1 shows the light-scattering geometry during the twilight. In the dawn segment, the sky may be brighter for two reasons. First, the height of the Earth's shadow is smaller there, while the denser atmospheric layers are illuminated by the Sun for a longer period. The difference in the effective height of the shadow increases during the dark twilight, and this factor mostly influences the phenomena in the upper atmospheric layers, like that of noctilucent clouds [23-25]. Second, the prevailing direction of the light scattering by aerosol particles is that under small angles to the incoming radiation, which strengthens the glow in the dawn segment. Both effects are quite noticeable in the diagram for the ratio of the values of the sky-background intensity at symmetric points of the solar vertical circle $I(\zeta) / I(-\zeta)$ versus solar zenith angle $z$. Figure 2 shows these dependences for the volcanically clear stratosphere in 2018 and the stratosphere in the period of purple lights in 2019 (solid curves). The brightness is asymmetric for dark twilight in the both cases (the right part of the diagram), while the aerosol effect (the left part of the diagram) reveals itself in 2019.

The effects of scattering by aerosols are also noticeable in the diagram of the sky background polarization versus the solar zenith angle, which is shown in Fig. 3 for the zenith case $\left(\zeta=0^{\circ}\right)$. During the transparent clear-sky twilight, the stratospheric aerosol background is characterized by high polarization that reaches 0.8 . In the fall of 2019, the polarization is substantially lower during a whole twilight period, including a dark phase, when the troposphere and stratosphere are immersed in the Earth's shadow. As we will see below, this is connected with the multiple scattering of light, in particular, by stratospheric aerosol particles. A total effect of the scattering by aerosols diminishes the polarization of the sky background at sunrise to approximately 0.5 at the zenith.

In this paper, the properties of the aerosol that cause the effect of purple lights are retrieved by the method developed for variable sizes of particles [18]. The method is based on the numerical integration of the single scattering and the use of empiric properties of the multiple scattering. The results may show how strongly the aerosol origin may be connected with the Raikoke volcanic eruption. 


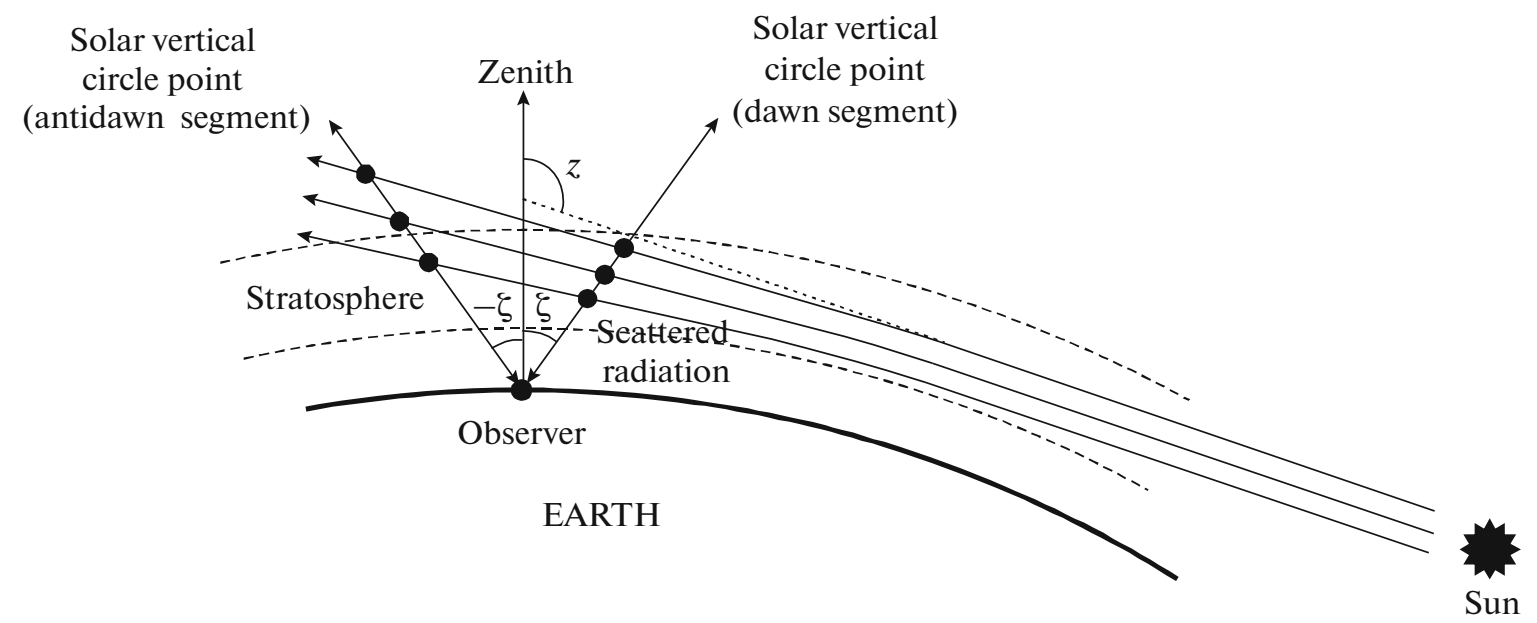

Fig. 1. Light-scattering geometry during twilight.

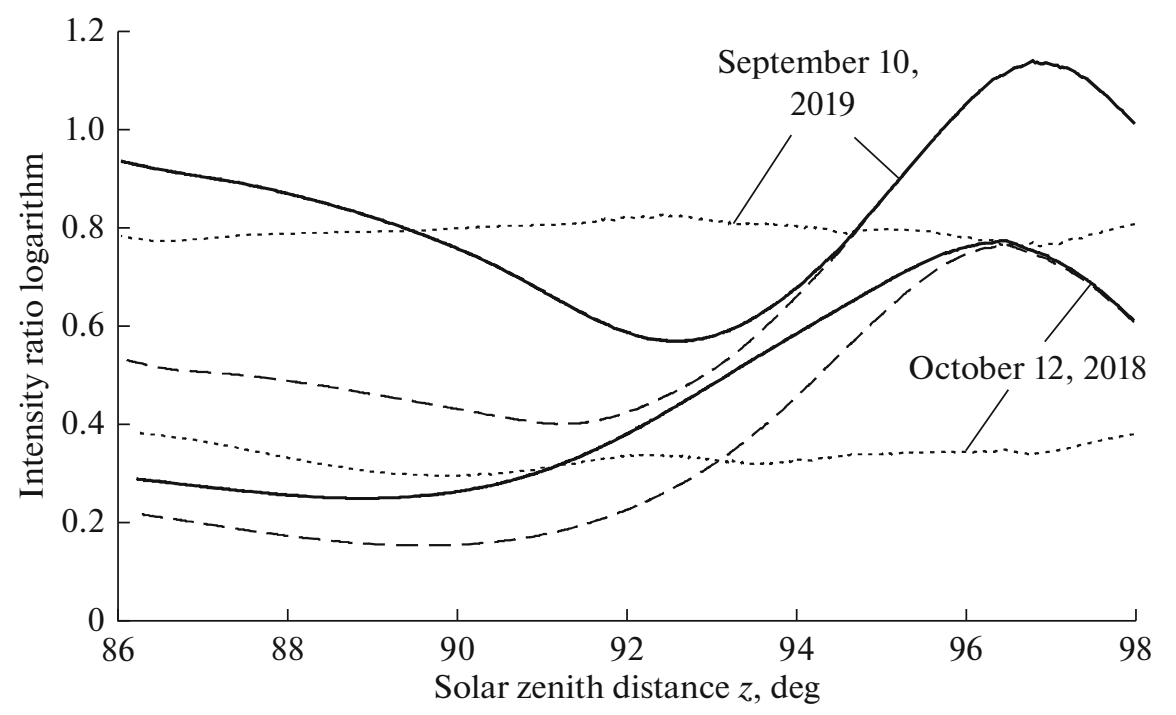

Fig. 2. Logarithm of the ratio of the intensity values at symmetric points of the solar vertical circle $\left(\zeta=45^{\circ}\right)$ for the whole sky background ( $I$, solid curves), the case without single scattering by the aerosol ( $I_{\mathrm{C}}$, dashed curves), and multiple scattering $\left(j_{\mathrm{M}}\right.$, dotted curves) during twilight in the fall of 2018 and 2019.

\section{RETRIEVING THE AEROSOL PROPERTIES}

A procedure for retrieving the properties of the aerosol component resembles that described and used in a paper [18]. Let $I(\zeta, z)$ and $P(\zeta, z)$ be the measured values of intensity and polarization (the first component of the Stokes vector and the second one normalized) of the sky background, where $z$ is the solar zenith angle and $\zeta$ is the zenith angle of a point at the solar vertical circle, with $\zeta$ being positive in the dawn domain and negative in the opposite part of the sky (see Fig. 1). For the same values of $z$ and $\zeta$, the theoretical values for the intensity of single scattering by molecules (the Rayleigh component) and aerosols are designated as $J_{0 R}\left(\zeta, z, A_{i}\right)$ and $J_{0 A}\left(\zeta, z, r_{0}, A_{i}\right)$, respec- tively. Here, the size distribution of aerosol particles is assumed to be lognormal with median radius $r_{0}$ and distribution width $\sigma=1.6[4,26-28]$ :

$$
f(r)=\frac{1}{\sqrt{2 \pi} \zeta r} \exp \left(\frac{-\ln ^{2}\left(r / r_{0}\right)}{2 \zeta^{2}}\right) ; \quad \zeta=\ln \sigma .
$$

Parameters $A_{i}$ are the ratios of the extinction coefficients of aerosols and molecules at altitudes $h_{i}$. These altitudes are defined on the $5-\mathrm{km}$ grid and equal to 5 , $10, \ldots, 60 \mathrm{~km}$. Since the aerosol diminishes the solar radiation before the scattering, the molecular scattering intensity $J_{0 R}$ also depends on parameters $A_{i}$. The polarization values for the molecular and aerosol scat- 


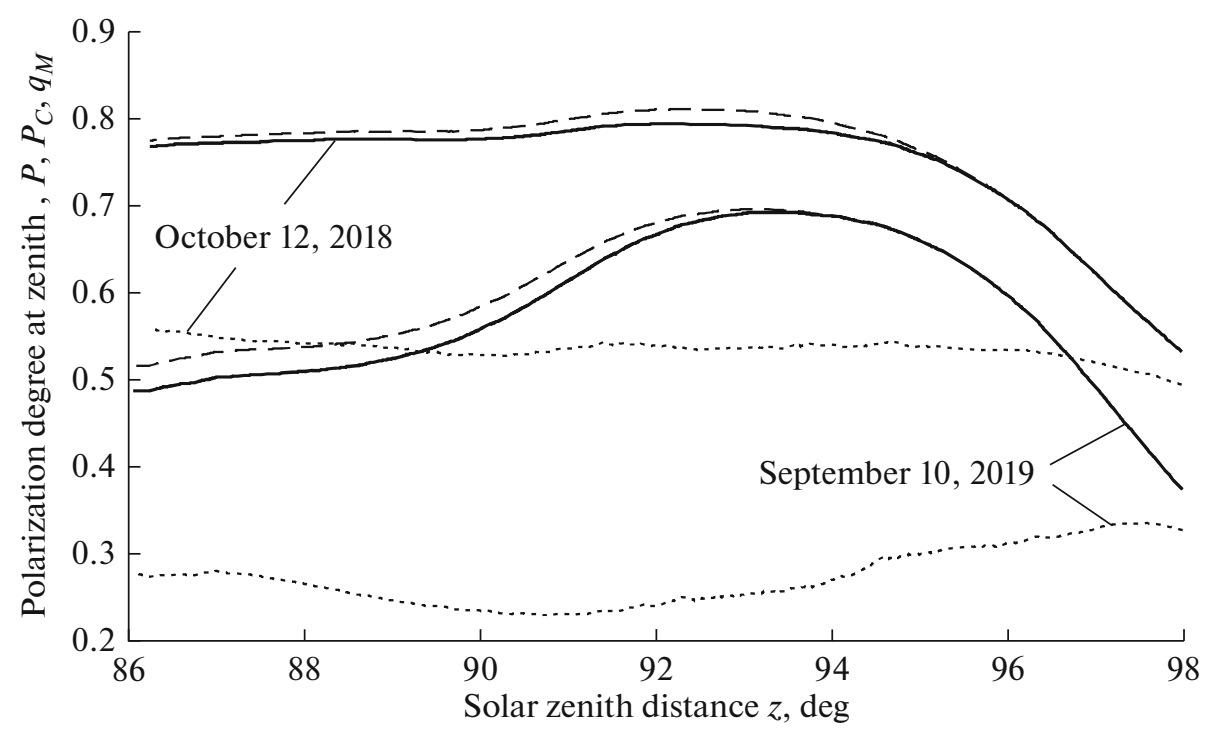

Fig. 3. Polarization degree at zenith for the whole sky background ( $P$, solid curves), the case without the single scattering by aerosols ( $P_{C}$, dashed curves), and the multiple scattering ( $q_{M}$, dotted curves) during twilight in the fall of 2018 and 2019.

tering $p_{0}(z-\zeta)$ and $p_{A}(z-\zeta, r)$ are defined by the Rayleigh and Mie theories, respectively. The single scattering occurs at an angle of $z-\zeta$, and the influence of refraction on this value is negligible (however, the refraction is important for calculating the trajectories of the radiation propagation). The refractive index of a sulfate particle is assumed to be 1.44 [29].

The single-scattering field for each of the observational dates was calculated in theory by taking into account the molecular and aerosol scattering, the refraction, and the ozone absorption in the Chappuis bands. For this purpose, the EOS Aura/MLS profiles of the temperature and the ozone concentration were used [20,30]. The intensity values for the Rayleigh and aerosol single scattering determined in observations are

$$
\begin{gathered}
J_{R}\left(\zeta, z, A_{i}\right)=J_{0 R}\left(\zeta, z, A_{i}\right)\left(K_{1}+K_{2} \zeta^{2}\right) ; \\
J_{A}\left(\zeta, z, r_{0}, A_{i}\right)=J_{0 A}\left(\zeta, z, r_{0}, A_{i}\right)\left(K_{1}+K_{2} \zeta^{2}\right) .
\end{gathered}
$$

The values of parameters $K_{1}$ and $K_{2}$ are initially unknown. They are influenced by the sensitivity and the flat field of the camera and possible uncertainties in the atmospheric transparency measured by the star images in the night sky frames. By subtracting this field from the measured sky background, we derive the intensity and polarization of the multiple-scattering component:

$$
\begin{gathered}
j_{M}=I-J_{R}-J_{A} ; \\
q_{M}=\frac{I P-J_{R} p_{R}-J_{A} p_{A}}{I-J_{R}-J_{A}} .
\end{gathered}
$$

One empirical property of the multiple scattering, which was determined from the dark twilight observations [21, 22, 31, 32], is the similarity of the intensity and polarization gradients at symmetric points of the solar vertical circle:

$$
\begin{aligned}
\frac{d \ln j_{M}(\zeta, z)}{d z} & =\frac{d \ln j_{M}(-\zeta, z)}{d z} ; \\
\frac{d q_{M}(\zeta, z)}{d z} & =\frac{d q_{M}(-\zeta, z)}{d z} .
\end{aligned}
$$

Following paper [18], we use this property as a criterion for the procedure of searching for the values of $r_{0}, A_{i}, K_{1}$, and $K_{2}$ with the least-squares method:

$$
\begin{aligned}
& \sum_{z} \sum_{\zeta}\left(\frac{d \ln j_{M}(\zeta, z)}{d z}-\frac{d \ln j_{M}(-\zeta, z)}{d z}\right)^{2} \\
& +\left(\frac{d q_{M}(\zeta, z)}{d z}-\frac{d q_{M}(-\zeta, z)}{d z}\right)^{2}=\min .
\end{aligned}
$$

The problem is solved with a multistep iteration routine: during each of the rounds, the $K_{1}$ and $K_{2}$ values are first determined from the data obtained during dark twilight, when the single-scattering contribution of aerosols is small $\left(96^{\circ}<z<99^{\circ}\right)$. After that, all of the other unknown quantities may be found. To fix the scattering by aerosols near the tropopause, it is necessary to consider the lower 5-km layer, which corresponds to parameter $A_{1}$, and to widen the zenith angle interval to the values in a range of $86^{\circ}<z<98^{\circ}$ (in paper [18], the lower layer was $10 \mathrm{~km}$ in height and the zenith angles of the Sun ranged from $90^{\circ}$ to $98^{\circ}$ ).

At the first stage, the model with a constant median radius of particles $r_{0}$ is used. Table 1 (left column) shows the values of $r_{0}$ for autumn twilights in 2018 and 2019. They are close to $0.1 \mu \mathrm{m}$, which agrees with the median radius of particles measured in balloon experiments $[4,6]$ and the estimates obtained from the 


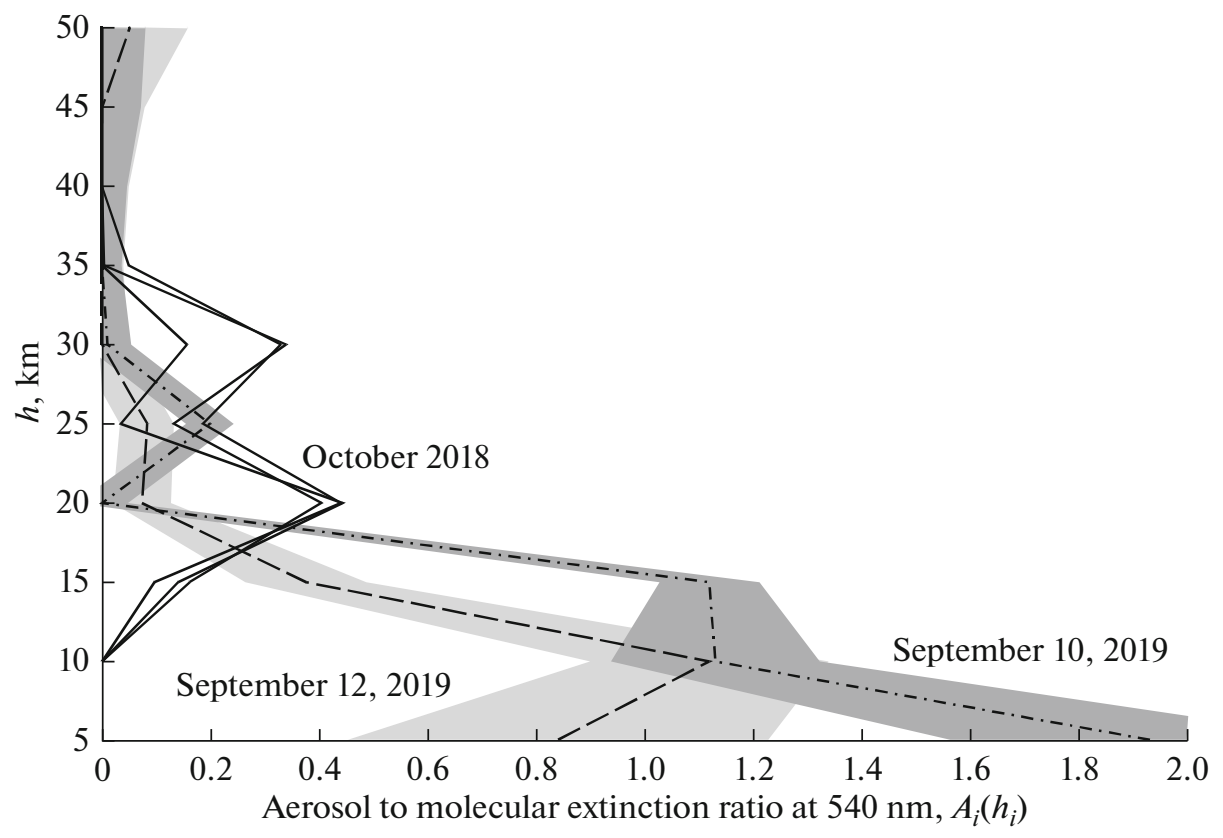

Fig. 4. Vertical profiles for the ratio of the aerosol and molecular extinctions in 2018 (solid curves) and 2019 (dashed and dash-dotted curves with error belts).

approximate analysis of the color and polarization of the twilight sky $[27,28]$ under background conditions. A close value $(0.08 \mu \mathrm{m})$ was taken a priori in the analysis of the limb measurements performed with the Optical Spectrograph and InfraRed Imager System (OSIRIS) onboard the Odin spacecraft [26].

Figure 4 shows the vertical profiles for the ratio of the aerosol and molecular extinctions retrieved in the analysis described above (the $A_{i}$ values). For the autumn of 2018, a typical Junge layer in the stratosphere is seen. The additional scattering by aerosols appears in the upper troposphere and near the tropopause in the autumn of 2019. Its expansion to higher stratospheric layers is not so significant; and the profile of September 10, 2019, is apparently represented by two separate layers.

To estimate the size of aerosol particles in the lower layer $(5-15 \mathrm{~km})$ in 2019 more accurately, it is necessary to run the procedure with a fixed value of $0.1 \mu \mathrm{m}$ for median radius $r_{0}$ at higher altitudes (above $20 \mathrm{~km}$ ). The results are presented in the right column of Table 1 . The median radius of the lower fraction turns out to be a little larger $(0.11 \mu \mathrm{m})$, and the difference is below the typical error of determining the $r_{0}$ value with the above method. The same value, $0.11 \mu \mathrm{m}$, results from the polarization analysis of the twilight sky after the Rabaul volcanic eruption in 2006 [33].

Figures 2 and 3 show the characteristics of the clear-sky background obtained by subtracting the single-scattering field of the aerosol (dashed curves). They are the ratio of the intensity values at symmetrical points of the solar vertical circle (expressed in logarithms) and the polarization at the zenith:

$$
\begin{gathered}
\ln \frac{I_{C}(\zeta, z)}{I_{C}(-\zeta, z)}=\ln \frac{I(\zeta, z)-J_{A}(\zeta, z)}{I(-\zeta, z)-J_{A}(-\zeta, z)} ; \\
P_{C}(0, z)=\frac{I(0, z) P(0, z)-J_{A}(0, z) P_{A}(0, z)}{I(0, z)-J_{A}(0, z)} .
\end{gathered}
$$

Table 1. Median radius of particles $r_{0}$ for the lognormal distribution with width $\sigma=1.6$; it was retrieved as a common quantity for all altitudes and separately for altitudes of $5-15 \mathrm{~km}$ under the assumption that $r_{0}=0.1 \mu \mathrm{m}$ in the upper layers

\begin{tabular}{l|c|c}
\hline \multicolumn{1}{c|}{$\begin{array}{c}\text { Date } \\
\text { (morning twilight) }\end{array}$} & $\begin{array}{c}\text { Median radius } \\
\text { (common for all layers) }\end{array}$ & $\begin{array}{c}\text { Median radius at 5-15 km } \\
\text { (a value of } r_{0}=0.1 \mu \mathrm{m} \text { is fixed at higher altitudes) }\end{array}$ \\
\hline October 12, 2018 & $0.102 \pm 0.011$ & - \\
October 17, 2018 & $0.113 \pm 0.023$ & - \\
October 20, 2018 & $0.091 \pm 0.019$ & $0.110 \pm 0.011$ \\
September 10, 2019 & $0.111 \pm 0.012$ & $0.107 \pm 0.024$ \\
September 12, 2019 & $0.101 \pm 0.025$ & - \\
\hline
\end{tabular}


Analogous characteristics of the multiple scattering $\left(\ln j(\zeta, z) / j(-\zeta, z)\right.$ and $\left.q_{\mathrm{M}}(0, z)\right)$ are shown by dotted curves in the same diagrams. It is seen that the multiple scattering maintains almost constant the ratio of the intensity values at symmetrical points of the solar vertical circle and the polarization during twilight, which completely satisfies criterion (4). The increase in the aerosol amount influences the multiple scattering by diminishing its polarization and strengthening the asymmetry in the sky brightness during the entire twilight period. It is the multiple scattering by aerosols that is the main cause of the decrease in the sky background polarization. This effect explains the correlation between the polarization values in the transparent and dark twilight phases, although the single scattering takes place in completely different layers of the atmosphere [34].

\section{DISCUSSION AND CONCLUSION}

In this paper, the polarization analysis of the twilight-sky background was used to reveal the additional scattering by aerosols and to estimate their mean radius in the epoch of purple lights in the early fall of 2019. The aerosol layer turned out to be mainly located in the upper troposphere with some extension to the stratosphere. It lies substantially lower than the Junge layer of the background stratospheric aerosol. This may be explained by the fact that the altitude of the Raikoke eruption plume did not exceed $15 \mathrm{~km}$. Sulfur dioxide may produce sulfate aerosols at these altitudes, while OCS is oxidized at higher altitudes.

Analysis of the Cloud-Aerosol Lidar and Infrared Pathfinder Satellite Observation (CALIPSO) satellite data on the aerosol extinction after the Kasatochi volcanic eruption in 2008 [10] showed that the layer was gently sinking into the tropopause and the upper troposphere for several months after the eruption. It is worth noting that, according to the satellite data acquired during the observations, the tropopause altitude was $11 \mathrm{~km}$ [20], which is close to the mean altitude of the aerosol obtained. At the same altitude, south of Moscow, there are eastward transit airways; and the shadows of inversion layers from airplanes were often observed against the purple light background.

Judging by the obtained altitude value, the volcanic aerosol cannot play any role in condensation of particles in the polar stratospheric clouds at the northern latitudes during the winter of 2019-2020. They are formed in the domain of the deep temperature minimum $(<190 \mathrm{~K}$ and above $21 \mathrm{~km})$ under conditions of a powerful polar stratospheric vortex of that winter.

According to the Mie theory, a strong dependence of the polarization of the scattered radiation on the median size of particles makes polarimetry an effective tool in the analysis of microphysical properties of aerosols. The median radius amounts to $0.11 \pm 0.02 \mu \mathrm{m}$, which corresponds to weak or moderate eruptions. In general, the observed properties of the aerosol confirm that it is related with the Raikoke volcanic eruption in June 2019.

\section{OPEN ACCESS}

This article is licensed under a Creative Commons Attribution 4.0 International License, which permits use, sharing, adaptation, distribution and reproduction in any medium or format, as long as you give appropriate credit to the original author(s) and the source, provide a link to the Creative Commons license, and indicate if changes were made. The images or other third party material in this article are included in the article's Creative Commons license, unless indicated otherwise in a credit line to the material. If material is not included in the article's Creative Commons license and your intended use is not permitted by statutory regulation or exceeds the permitted use, you will need to obtain permission directly from the copyright holder. To view a copy of this license, visit http://creativecommons.org/licenses/by/4.0/.

\section{REFERENCES}

1. Junge, C.E., Changnon, C.W., and Manson, J.E., Stratospheric aerosols, J. Meteorol., 1961, vol. 18, pp. 81-108.

2. Rosen, J.M., The boiling point of stratospheric aerosols, J. Appl. Meteorol., 1971, vol. 10, pp. 1044-1046.

3. Weisenschtein, K.D., Yue, G.K., Ko, M.K.W., et al., A two-dimensional model of sulfur species and aerosol, J. Geophys. Res., 1997, vol. 102, pp. 13019-13035.

4. Deshler, T., Hervig, M.E., Hofmann, D.J., et al., Thirty years of in situ stratospheric aerosol size distribution measurements from Laramie, Wyoming $\left(41^{\circ} \mathrm{N}\right)$, using balloon-borne instruments, J. Geophys. Res., 2003, vol. 108, no. D5, pp. 4167-4179.

5. Clark, J.E., The remarkable sunsets, Nature, 1883, vol. 29, p. 130.

6. Deshler, T., et al., Trends in the nonvolcanic component of stratospheric aerosol over the period 19712004, J. Geophys. Res., 2006, vol. 111, id. D01201.

7. Bauman, J.J., Russell, P.B., Geller, M.A., and Hamill, P., A stratospheric aerosol climatology from SAGE II and CLAES measurements: 2. Results and comparisons, 1984-1999, J. Geophys. Res., 2003, vol. 108, no. D13, pp. 4383-4412.

8. Lee, R., Jr. and Hernandez-Andres, J., Measuring and modeling twilight's purple light, Appl. Opt., 2003, vol. 42, pp. 445-457.

9. Crutzen, P.J., The possible importance of CSO for the sulfate layer of the stratosphere, Geophys. Res. Lett., 1976, vol. 3, pp. 73-76.

10. Andersson, S.M., Martinsson, B.G., Vernier, J.-P., et al., Significant radiative impact of volcanic aerosol in the lowermost stratosphere, Nat. Commun., 2015, vol. 6, id. 7692.

11. Solomon, S., Daniel, J.S., Neely, R.R., et al., The persistently variable "background" stratospheric aerosol layer and global climate change, Science, 2011, vol. 333, pp. 866-870. 
12. Campbell, J.E., Whelan, M.E., Seibt, U., Smith, S.J., et al., Atmospheric carbonyl sulfide sources from anthropogenic activity: implications for carbon cycle constraints, Geophys. Res. Lett., 2015, vol. 42, pp. 30043010 .

13. Aydin, M., Fudge, T.J., Verhulst, K.R., et al., Carbonyl sulfide hydrolysis in Antarctic ice cores and an atmospheric history for the last 8000 years, J. Geophys. Res., 2014, vol. 119, pp. 8500-8514.

14. Neely, R.R., Toon, O.B., Solomon, S., et al., Recent anthropogenic increases in $\mathrm{SO}_{2}$ from Asia have minimal impact on stratospheric aerosol, Geophys. Res. Lett., 2013, vol. 40, pp. 999-1004.

15. Bourassa, A.E., Robock, A., Randel, W.J., et al., Large volcanic aerosol load in the stratosphere linked to Asian monsoon transport, Science, 2012, vol. 337, pp. 78-81.

16. Ridley, D.A., et al., Total volcanic stratospheric aerosol optical depths and implications for global climate change, Geophys. Res. Lett., 2014, vol. 41, pp. 77637769.

17. Kremser, S., et al., Stratospheric aerosol-observations, processes, and impact on climate, Rev. Geophys., 2016, vol. 54, pp. 278-335.

18. Ugolnikov, O.S. and Maslov, I.A., Optical depths and vertical profiles of stratospheric aerosol based on multiyear polarization measurements of the twilight sky, J. Aerosol Sci., 2019, vol. 127, pp. 93-101.

19. Crafford, A.E. and Venzke, E., Global Volcanism Program. Report on Raikoke (Russia), Bulletin of the Global Volcanism Network, Washington, DC: Smithsonian Institution, 2019, vol. 44, no. 8. https://doi.org/10.5479/si.GVP.BGVN201908-290250

20. EOS MLS Science Team, MLS/Aura Level 2 Temperature, Version 003, Greenbelt, MD: NASA Goddard Earth Science Data and Information Services Center (GES DISC), 2011.

21. Ugolnikov, O.S. and Maslov, I.A., Optical properties of the undisturbed mesosphere from wide-angle twilight sky polarimetry, Cosmic Res., 2013, vol. 51, no. 4, pp. $235-240$.

22. Ugolnikov, O.S. and Maslov, I.A., Summer mesosphere temperature distribution from wide-angle polarization measurements of the twilight sky, J. Atmos. Sol.Terr. Phys., 2013, vols. 105-106, pp. 8-14.

23. Ugolnikov, O.S., Maslov, I.A., Kozelov, B.V., and Dlugach, J.M., Noctilucent cloud polarimetry: twilight measurements in a wide range of scattering angles, Planet. Space Sci., 2016, vol. 125, pp. 105-113.
24. Ugolnikov, O.S., Galkin, A.A., Pilgaev, S.V., and Roldugin, A.V., Noctilucent cloud particle size determination based on multi-wavelength all-sky analysis, Planet. Space Sci., 2017, vol. 146, pp. 10-19.

25. Ugolnikov, O.S. and Maslov, I.A., Polarization analysis and probable origin of bright noctilucent clouds with large particles in June 2018, Planet. Space Sci., 2019, vol. 179, p. 104713.

26. Bourassa, A.E., Degenstein, D.A., and Llewellyn, E.J., Retrieval of stratospheric aerosol size information from OSIRIS limb scattered sunlight spectra, Atmos. Chem. Phys. Discuss., 2008, vol. 8, pp. 4001-4016.

27. Ugolnikov, O.S. and Maslov, I.A., Investigations of the background stratospheric aerosol using multicolor wide-angle measurements of the twilight glow background, Cosmic Res., 2018, vol. 56, no. 2, pp. 85-93.

28. Ugolnikov, O.S. and Maslov, I.A., Stratospheric aerosol particle size distribution based on multi-color polarization measurements of the twilight sky, J. Aerosol Sci., 2018, vol. 117, pp. 139-148.

29. Russell, P.B. and Hamill, P., Spatial variation of stratospheric aerosol acidity and model refraction index: Implication of recent results, J. Atmos. Sci., 1984, vol. 41, pp. 1781-1790.

30. EOS MLS Science Team, MLS/Aura Level 2 Ozone (O3) Mixing Ratio V003, Greenbelt, MD: Goddard Earth Sciences Data and Information Services Center (GES DISC), 2011.

31. Ougolnikov, O.S., Twilight sky photometry and polarimetry: The problem of multiple scattering at the twilight time, Cosmic Res., 1999, vol. 37, no. 2, pp. 159166.

32. Ougolnikov, O.S. and Maslov, I.A., Multicolor polarimetry of the twilight sky: The role of multiple light scattering as a function of wavelength, Cosmic Res., 2002, vol. 40, no. 3, pp. 224-232).

33. Ugolnikov, O.S. and Maslov, I.A., Studies of the stratosphere aerosol layer based on polarization measurements of the twilight sky, Cosmic Res., 2009, vol. 47, no. 3, pp. 198-207.

34. Ugolnikov, O.S. and Maslov, I.A., Detection of Leonids meteoric dust in the upper atmosphere by polarization measurements of the twilight sky, Planet. Space Sci., 2007, vol. 55, pp. 1456-1463.

Translated by E. Petrova 